\title{
Avaliação microbiológica, histológica e imunológica de frangos de corte desafiados com Salmonella Enteritidis e Minnesota e tratados com ácidos orgânicos ${ }^{1}$
}

\author{
Larissa Pickler²*, Ricardo M. Hayashi² ${ }^{2}$ Mariana C. Lourenço² ${ }^{2}$ Leonardo B. Miglino², \\ Luiz Felipe Caron ${ }^{3}$, Breno C.B. Beirão ${ }^{3}$, Ana V.F. Silva ${ }^{4}$ e Elizabeth Santin ${ }^{2}$
}

\begin{abstract}
Pickler L., Hayashi R.M., Lourenço M.C., Miglino L.B., Caron L.F., Beirão B.C.B., Silva A.V.F. \& Santin E. 2012. [Microbiology, histology and immunology evaluation of broiler chickens challenged against Salmonella Enteritidis and Minnesota and treated with organic acids.] Avaliação microbiológica, histológica e imunológica de frangos de corte desafiados com Salmonella Enteritidis e Minnesota e tratados com ácidos orgânicos. Pesquisa Veterinária Brasileira 32(1):27-36. Laboratório de Microbiologia e Ornitopatologia, Departamento de Medicina Veterinária, Universidade Federal do Paraná, Rua dos Funcionários 1540, Curitiba, PR 80035-050, Brazil. E-mail: larissapickler@yahoo.com.br

Two experiments were carried out to evaluate effectiveness of organic acids against Salmonella enterica enterica serovars Enteritidis (SE) and Minnesota (SM) in broilers. In the first experiment three treatments were evaluated: T1 - feeding with organic acids, T2 - feeding with organic acids and organic acids in drink water, and T3 - control group. All animals were oral challenged with SE. Organic acids in diet (T1) and organic acids in diet and drink water (T2) reduced the shadding of Salmonella in crop and cecum 7 days post challenged with SE and reduced the CD3+ cells in jejunal mucosa of broilers. In the second experiment four treatments were evaluated, T1 - control group, T2 - control group oral challenged with Salmonella Minnesota (SM); T3 - oral challenged animals with SM and treated with organic acids in diet; T4 - oral challenged animals with SM and treated with organic acids in diet and in drink water. Organic acids in diet (T3) and organic acids in diet and in drink water (T4) reduced the shadding of SM in crop of challenged broilers, 7 days post inoculation The use of organic acids in diet and in water was more effective to control SE than SM.
\end{abstract}

INDEX TERMS: Goblet cells, CD3+ cells, flow citometric, imunohistochemistry.

RESUMO.- Dois experimentos foram desenvolvidos para avaliar a eficiência de ácidos orgânicos frente a Salmonella enterica enterica sorovar Enteritidis (SE) e Minnesota (SM) em frangos. No primeiro experimento foram avaliados 3 tratamentos: T1 - ração adicionada de ácido

\footnotetext{
${ }^{1}$ Recebido em 23 de julho de 2011.

Aceito párea publicação em 21 de setembro de 2011.

${ }^{2}$ Laboratório de Microbiologia e Ornitopatologia, Departamento de Medicina Veterinária, Universidade Federal do Paraná, Campus Juvevê, Rua dos Funcionários 1540, Curitiba, PR 80035-050, Brasil. *Autor para correspondência: larissapickler@yahoo.com.br

${ }^{3}$ Setor de Ciências Biológicas, Departamento Patologia Básica, Centro Politécnico, Universidade Federal do Paraná, Cx. Postal 19031, Curitiba, PR.

${ }^{4}$ Setor de Ciências Biológicas, Departamento de Fisiologia, Centro Politécnico, Universidade Federal do Paraná, sala 89, Cx. Postal 19031, Curitiba, PR.
}

orgânico, T2 - ração adicionada de ácido orgânico e ácido orgânico na água de bebida, T3 - grupo controle. Todos os animais foram inoculados com SE, via oral. A utilização de ácidos orgânicos na ração (T1) e na ração e na água (T2) diminuíram a excreção de Salmonella no papo e no ceco 7 dias pós inoculação com SE e houve redução de células CD3+ no jejuno dos frangos. No segundo experimento foram avaliados 4 tratamentos sendo T1 - controle, T2 - controle inoculado via oral com Salmonella Minnesota (SM), T3 - animais inoculados via oral com SM e ácidos orgânicos na ração e T4 - animais inoculados via oral com SM e ácidos orgânicos na ração e na água de bebida. Ácidos orgânicos a ração (T3) e na ração e na água (T4) reduziram a excreção de SM em papo de frangos de corte desafiados, 7 dias após inoculação. 0 uso de ácidos orgânicos na ração e na ração e na água foram mais eficientes em reduzir SE do que SM. 
TERMOS DE INDEXAC̄̃̃O: Células caliciformes, células CD3+; citometria de fluxo; imuno-histoquímica.

\section{INTRODUÇÃO}

A Salmonelose é uma enfermidade de importância mundial que preocupa as autoridades sanitárias e se constitui em importante barreira ao comércio internacional de alimentos devido seu potencial zoonótico. A ampla distribuição de Salmonella entre os animais e sua capacidade de sobreviver por longos períodos no meio ambiente contribuem para seu destacado papel em saúde pública (Butaye et al. 2003). 0 gênero Salmonella pertence à família Enterobacteriaceae e compreende as espécies $S$. enterica e $S$. bongori; a espécie S. enterica alberga as linhagens patogênicas distribuídas em seis subespécies e 2.564 sorovares, todas patogênicas ao homem (Bopp et al. 2003) onde incluem-se a Salmonella enterica enterica sorovar Enteritidis (SE) e a Salmonella enterica enterica sorovar Minnesota (SM).

No período de 1996 a 2006, nos Estados Unidos, foram diagnosticados 75.058 casos de $S$. Typhimurium; 69.547 casos de $S$. Enteritidis e 340 casos de $S$. Minnesota em seres humanos (Centers of Disease Control, 2008). A Salmonella Enteritidis e a Salmonella Typhimurium também são os sorovares mais frequentemente isolados em produtos de origem avícola, porém, atualmente, outros sorovares estão sendo isolados, dentre eles o Minnesota. É verdade, que, devido ao mecanismo de exclusão competitiva, alguns sorovares podem ser mais eficientes que outros em seu estabelecimento dentro da microbiota dos animais e que, uma vez estes sendo controlados, outros sorovares começam a ser mais freqüentemente isolados. Por outro lado, ainda não é possível afirmar se os atuais métodos de controle de salmonelose em frangos são realmente efetivos contra todos os sorovares identificados.

Um dos métodos atuais de controle da salmonelose em frangos é a adição de ácidos orgânicos na ração e na água dos animais. Como grupo químico, os ácidos orgânicos são considerados como sendo qualquer substância de estrutura geral R-COOH, gerando grupos de compostos relacionados, conhecidos como derivados dos ácidos carboxílicos, como os aminoácidos, ácidos graxos, coenzimas e metabólitos intermediários (Solomon \& Fhyhle, 2002). Aqueles associados com atividade antimicrobiana são os ácidos graxos de cadeia curta, tanto monocarboxílicos, como fórmico, acético, propiônico e o butírico ou carboxilados com o grupo hidroxila como lático, málico, tartárico e o cítrico. 0 principal mecanismo de ação dos ácidos seria devido à redução do pH no interior da célula bacteriana, o que levaria à atividade antimicrobiana (Cherrington et al. 1991, Roth \& Kirchgessner, 1998). De acordo com provável mecanismo, a forma não dissociada do ácido seria lipossolúvel e nessa forma teria capacidade de atravessar de forma passiva a membrana celular. No interior da célula, o ácido se dissociaria alterando o $\mathrm{pH}$ citoplasmático, modificando o gradiente de prótons e a carga elétrica com o exterior celular. Isso interferiria no sistema de transporte de aminoácidos e fosfatos além de inativar enzimas (Russel, 1992). Outra consequência seria o aumento da pressão osmótica celular devido aos mecanismos de compensação de carga elétrica aumentando os níveis de sódio, potássio ou glutamato e a força iônica intracelular, provocando um aumento da pressão mecânica sobre a parede do microorganismo, o que faria com que essa se rompesse (Russel 1992). Entretanto, outros autores (Stratford et al. 2009) demonstraram que nem todos os ácidos orgânicos necessitam reduzir o pH no citoplasma para exercer sua atividade antimicrobiana. Por exemplo, no caso do ácido sórbico, observa-se que concentrações inibitórias deste ácido não reduzem o pH citoplasmático e acredita-se que a membrana citoplasmática seja o primeiro sítio de ação deste ácido. A lesão da membrana, a perda da sua integridade e o aumento a permeabilidade a prótons causariam a morte do microorganismo.

O objetivo do presente estudo foi conhecer e avaliar a capacidade de redução de Salmonella com o uso de ácidos orgânicos via ração e via ração e água em aves desafiadas com Salmonella enterica enterica sorovar Enteritidis (SE) e sorovar Minnesota (SM).

\section{MATERIAL E MÉTODOS}

Foram desenvolvidos dois experimentos sendo o Experimento 1 com animais inoculados via oral com Salmonella Enteritidis (SE) na concentração $10^{5} \mathrm{UFC} / \mathrm{mL}$ e o Experimento 2 com animais inoculados via oral com Salmonella Minnesota (SM) na concentração $10^{8} \mathrm{UFC} / \mathrm{mL}$. Toda metodologia de estudo foi avaliada e aprovada pelo Comitê de Ética em experimentação animal do Setor de Ciências Agrárias da Universidade Federal do Paraná com protocolo número 008/2009.

\section{Experimento 1}

Animais, dietas e ambiente. Foram alojados 180 frangos de corte distribuídas em 3 tratamentos, com 4 repetições de 15 animais cada em delineamento experimental inteiramente casualizado, sendo T1 - ração adicionada de ácidos orgânicos (mistura comercial Neoacid® - ácido lático - $140 \mathrm{~g} / \mathrm{kg}$ - ácido fumárico $45 \mathrm{~g} / \mathrm{kg}$ - ácido cítrico - $50 \mathrm{~g} / \mathrm{kg}$ - ácido fórmico - $100 \mathrm{~g} / \mathrm{kg})(2 \mathrm{~kg} /$ ton), T2 - ração adicionada de ácidos orgânicos (2kg/ton) e ácidos orgânicos na água de bebida (Acidificante Solúvel Sanex®, composto de ácido fumárico - $270 \mathrm{~g} / \mathrm{kg}$ e ácido cítrico - $280 \mathrm{~g} / \mathrm{kg}$ ) (120g/1000L) durante 5 dias após inoculação com SE e T3 - grupo controle inoculado com SE, sem adição de ácidos orgânicos na ração ou na água. Os produtos adicionados na ração e na água das aves foram fornecidos de acordo com recomendações do fabricante.

Os animais dos tratamentos 1 e 2 receberam a mistura comercial de ácidos orgânicos na ração desde o primeiro até o último dia de vida. E os animais do tratamento 2 passaram a receber o ácido orgânico na água de bebida, $24 \mathrm{~h}$ após a inoculação com SE, por um período de 5 dias.

As aves foram mantidas do $1^{\circ}$ ao $21^{\circ}$ dia de vida em temperatura ideal de conforto para a idade das aves, com fornecimento de água e ração à vontade, sendo alimentadas com ração balanceada em níveis iguais ou superiores recomendados pelo National Research Council (NRC 1994), sem presença de coccidiostático e promotores de crescimento. Foram alojados em baterias experimentais em mesma sala experimental sem a presença de um grupo controle não inoculado.

Desempenho zootécnico. Para avaliação do desempenho zootécnico, do $1^{\circ}$ ao $21^{\circ}$ dia de vida, as aves, a ração fornecida e as sobras foram pesadas para cálculo da ração consumida, ganho de peso e conversão alimentar, a qual foi calculada dividindo-se a ração consumida pelo ganho de peso das aves. As aves que mor- 
reram também foram pesadas para correção do ganho de peso e conversão alimentar.

Cepa e inoculação. Para o preparo do inóculo, uma colônia pura de Salmonella Enteritidis foi retirada do Ágar estoque e incubada em solução de BHI (Brain Heart Infusion) por $24 \mathrm{~h}$ a $37^{\circ} \mathrm{C}$. Em seguida, semeou-se com swab esta solução em uma placa de Agar Mueller Hinton por $24 \mathrm{~h}$ a $37^{\circ} \mathrm{C}$. A seguir a placa foi lavada, com solução de $\mathrm{NaCl} 0,85 \%$ esterilizada. A cultura bacteriana foi diluída seriadamente (1:10), também em solução $\mathrm{NaCl}$ esterilizada, até que se alcançasse a concentração correspondente à escala 0,5 de MacFarland, a qual corresponde à concentração de $10^{8} \mathrm{de}$ UFC (Unidades Formadoras de Colônias) de Salmonella Enteritidis/mL. Foram realizadas diluições seriadas em tubos contendo $9 \mathrm{~mL}$ de $\mathrm{NaCl}$ 0,85\% esterilizada até atingir a concentração de $10^{5} \mathrm{UFC} / \mathrm{mL}$. Cada uma das diluições foi semeada em PCA (Plate Count Agar, Oxoid $囚$ ) para contagem de colônias.

Aos 14 dias de idade todos os animais foram inoculados com $1 \mathrm{~mL}$ de solução de Salmonella Enteritidis na concentração de $10^{5}$ $\mathrm{UFC} / \mathrm{mL}$ via oral.

Análise microbiológica. Foram realizados swabs de cloaca de todos os animais, 48 horas após inoculação com SE sendo 3 grupos de 5 animais por repetição (12 amostras por tratamento), para análise de contagem de Salmonella. No 21ํ dia de idade as aves foram eutanasiadas e necropsiadas, onde coletaram-se assepticamente, fragmentos de papo e ceco (aproximadamente $10 \mathrm{~g}$ de órgão e conteúdo) de 3 animais por repetição (12 amostras por tratamento), para análise de contagem de Salmonella.

Para realização do procedimento de contagem de Salmonella os swabs de cloaca, os papos e os cecos foram macerados e diluídos em água peptonada $2 \%$ em proporção de 1:9 (1g de fragmento para $9 \mathrm{~mL}$ de água peptonada). Retirou-se $1 \mathrm{~mL}$ da solução inicial de água peptonada $2 \%$ que foi pipetado no tubo contendo $9 \mathrm{~mL}$ de água peptonada $0,1 \%$ e assim sucessivamente, até a diluição $10^{-3}$. Posteriormente, retirou-se $100 \mu \mathrm{L}$ de cada diluição que foram dispensados em placas em duplicata em meio XLD (Xilose Lisina Desoxicolato, Oxoid $®$ ), espalhando-se o líquido pela superfície da placa com uma alça de vidro. As placas foram incubadas em estufa regulada a $35^{\circ} \mathrm{C}$ por $24 \mathrm{~h}$ e submetidas à posterior contagem das colônias típicas que foram submetidas à sorologia, com soro Polivalente, para confirmação e enviadas ao Instituto Oswaldo Cruz para tipificação (adaptado de Desmidt et al. 1998).

A solução inicial de água peptonada $2 \%$ foi incubada a $35^{\circ} \mathrm{C}$ por $24 \mathrm{~h}$. Após esse período, transferiram-se $100 \mu \mathrm{L}$ da solução inicial para tubos com $10 \mathrm{~mL}$ de caldo Rappaport-Vassiliadis e incubou-se em estufa $42^{\circ} \mathrm{C}$ por $24 \mathrm{~h}$, para confirmação da presença/ ausência de Salmonella.

Os resultados das contagens de colônias foram realizados de acordo com Procedimentos de Contagem de Colônia de acordo com a Normativa nํ62 publicada em 26 de agosto de 2003 (Brasil, MAPA).

Necropsia. Aos 21 dias de idade, 3 animais de cada repetição (12 por tratamento) foram eutanasiadas por deslocamento cervical e necropsiados para coleta de forma asséptica de papo e ceco para análise microbiológica. Também foram coletados fragmentos de duodeno, jejuno, íleo e ceco em formalina tamponada a $10 \%$ para avaliação histológica, morfométrica e imuno-histoquímica.

Histopatologia e morfologia intestinal. As amostras de duodeno, jejuno, íleo e ceco foram processadas rotineiramente para histologia e coradas com Alcian Blue para contagem de células caliciformes, de acordo com Smirnov et al. (2006). As variáveis avaliadas nos intestinos foram altura de vilo, profundidade de criptas, relação vilo/cripta e contagem de células caliciformes, com leitura de 20 vilos por tratamento em aumento de $40 \mathrm{x}$. As análises morfométricas do epitélio intestinal foram feitas em mi- croscopia de luz em sistema de captura de imagens acoplado a microscópio óptico.

Imuno-histoquímica. As seções de intestino para imuno-histoquímica foram desparafinadas em estufa a $60^{\circ} \mathrm{C}$ por $10 \mathrm{mi}-$ nutos e re-hidratadas em xilol e álcool. A recuperação antigênica foi realizada com Tampão Citrato $\mathrm{pH} \mathrm{6,0} \mathrm{em} \mathrm{banho-maria} 100^{\circ} \mathrm{C}$ por 20 minutos com bloqueio da peroxidase endógena com peróxido de hidrogênio a $3 \%$ e proteína bloqueadora, por 8 e 5 minutos, respectivamente. 0 anticorpo primário utilizado foi o anti-CD3, diluído 1:700 por 90 minutos. Para detecção da reação foi utilizado anticorpos secundários anti-coelho e anti-camundongo em um mesmo sistema de amplificação, kit ADVANCE®, por 40 minutos, utilizando-se, para revelação, um cromógeno, kit DAB ${ }$, por 5 minutos. A contra-coloração foi realizada com hematoxilina por 5 minutos após a desidratação e montagem das lâminas sinalizadas.

As análises imuno-histoquímicas dos segmentos intestinais foram feitas em microscopia de luz, em sistema analisador de imagens (Motic Images Plus 2,0-Motic China Group Co. 2006) acoplado a microscópio óptico (Olympus BH2 Olympus America Inc., NY, USA). Nas amostras de duodeno, jejuno, íleo e ceco foram realizadas a quantificação de células CD3 positivas por campo em aumento de 100x, com leitura de 10 vilos por tratamento.

Citometria de fluxo. Aos 21 dias de vida das aves, foram coletados sangue de 4 animais por tratamento utilizando anticoagulante heparina. As células mononucleares foram separadas do sangue total através de gradiente de densidade usando Histopaque-1077. A metodologia da citometria de fluxo foi previamente descrita por Fair et al. 2008. Os dados foram analisados com o "software FlowJo".

\section{Experimento 2}

Animais, dietas e ambiente. Foram alojados 72 frangos de corte distribuídas em 4 tratamentos com 18 animais cada em delineamento experimental inteiramente casualizado onde cada animal era uma repetição; sendo T1 - controle sem inoculação e sem adição de ácidos orgânicos, T2 - controle inoculado com Salmonella Minnesota (SM) e sem adição de ácidos orgânicos, T3 animais inoculados com SM e adição de ácidos orgânicos na ração (2kg/ton), e T4 - animais inoculados com SM e adição de ácidos orgânicos na ração (2kg/ton) e na água de bebida (120g/1000L) 3 dias após inoculação administrado durante 3 dias. Os produtos adicionados na ração e na água dos animais foram fornecidos de acordo com recomendações do fabricante.

Rações e ácidos orgânicos utilizados foram os mesmos do primeiro experimento. Os animais dos tratamentos 3 e 4 receberam a mistura comercial de ácidos orgânicos na ração desde o primeiro até o $28^{\circ}$ dia de vida. E os animais do tratamento 4 passaram a receber o ácido orgânico na água de bebida, $72 \mathrm{~h}$ após a inoculação com SM, por um período de 3 dias.

Neste experimento os animais foram alojados em salas individuais, com controle de ambiência, onde não existia contato entre os diferentes grupos, sendo possível a existência de um grupo não inoculado com SM.

A preparação do inóculo de Salmonella, análise microbiológica, análise histopatológica e de imuno-histoquímica foram iguais as descritas no Experimento 1.

Cepa e inoculação. Aos 21 dias de idade os animais dos tratamentos 2, 3 e 4 foram inoculados por via oral com $1 \mathrm{~mL}$ de solução de Salmonella Minnesota na concentração de $10^{8} \mathrm{UFC} / \mathrm{mL}$. A cepa de SM isolada de frangos de corte foi submetida à análise e tipificação no Instituto Oswaldo Cruz para confirmação do sorovar, assim como aquelas isoladas nas análises microbiológicas do experimento. 
Coleta de amostras para microbiologia, histopatologia e imuno-histoquímica. Foram realizados swabs de cloaca 48 horas pós inoculação de SM (22 dias de idade) para análise de contagem Salmonella. No $28^{\circ}$ dia de idade e sete dias após inoculação com SM, 18 aves por tratamento foram eutanasiadas e necropsiadas, para coleta de papo e ceco e análise de contagem Salmonella.

Análise estatística. As médias de contagem de unidades formadoras de colônia (UFC) de SE e SM foram transformadas em Log10 e submetidas ao teste T, ou quando não foi possível a contagem pela baixa expressão de UFC nas placas, as amostras positivas e negativas foram submetidas ao teste do Qui-quadrado $\left(\mathrm{x}^{2}\right)$. As médias de consumo de ração, ganho de peso e conversão alimentar, altura de vilosidade, profundidade de criptas, contagem de células caliciformes e contagem de células CD3+ foram submetidas ao teste de T. As células avaliadas em citometria de fluxo foram submetidas ao teste de Qui-quadrado.

Para comparar a eficácia do produto via água e via ração para os diferentes sorovares de Salmonella foi realizado o cálculo da porcentagem de redução de excreção de Salmonella em relação ao grupo controle inoculado de cada experimento e esta porcentagem de redução comparada pelo teste de Qui-quadrado.

\section{Experimento 1}

\section{RESULTADOS E DISCUSSÃO}

Desempenho zootécnico. No Quadro 1 encontram-se os resultados do desempenho zootécnico dos animais do $1^{\text {o }}$ ao $21^{\circ}$ dia de idade, onde foi avaliado o consumo de ração total (CRT), consumo de ração médio (CRM), ganho de peso total (GPT), ganho de peso médio (GPM) e conversão alimentar (CA). Não foram observadas diferenças significativas no período avaliado (1-21 dias de idade) e nos parâmetros zootécnicos avaliados $(\mathrm{P} \leq 0,05)$. Estudos avaliando o desempenho zootécnico de frangos de corte e o uso de ácidos orgânicos apresentam resultados controversos, provavelmente devido aos diferentes mecanismos de ação, condições ambientais, dose e produto utilizado e parâmetros avaliados. Diferentes níveis de inclusão de ácido acético em rações de frango experimentalmente contaminadas com Salmonella observaram que a inclusão do ácido orgânico em todos os níveis avaliados melhorou os parâmetros zootécnicos dos animais, porém, no que se refere ao controle microbiológico, o uso do produto não foi satisfatório (Rezende et al. 2008). Entretanto, mistura de ácidos fumárico $(0,5 \%)$, lático $(5,13 \%)$, cítrico $(5,4 \%)$ e ascórbico $(1,2 \%)$ na ração não melhorou os parâmetros zootécnicos de frangos de corte no período de 1 a 21 dias de idade (Maiorka et al. 2004).

Análise de Salmonella. No Quadro 2 estão apresentados os dados referentes à contagem de Salmonella Enteritidis (SE) em swabs de cloaca 48 horas pós inoculação (PI) com SE e de amostras positivas em relação ao total de amostras em ceco e papo 7 dias pós inoculação com SE. Para os sete dias PI, houve apenas crescimento bacteriano após enriquecimento em meio seletivo, de maneira que foi preferível utilizar o critério presença/ausência. Observa-se que a mistura de ácidos orgânicos na ração ou na ração e na água mostrou-se eficaz em combater a colonização de $\mathrm{SE}$ no ceco e no papo de frangos, reduzindo significativamente $(\mathrm{P} \leq 0,05)$ o número de amostras positivas para esta bactéria, quando comparado ao grupo controle. Entretanto, isso não se observa na contagem de amostras de swabs 48 horas após a inoculação, onde não houve diferença significativa entre os tratamentos.

Morfologia intestinal e imuno-histoquímica. No Quadro 3 estão apresentados os resultados relativos a tamanho de vilosidade $(\mu \mathrm{m})$, profundidade de criptas $(\mu \mathrm{m})$, relação vilo/cripta, contagem de células caliciformes e contagem de células CD3+/campo em duodeno, jejuno, íleo e ceco, aos 21 dias de idade, 7 dias pós inoculação nos diferentes tratamentos.

Com relação à altura de vilosidade em duodeno, obteve-se altura significativamente menor $(\mathrm{P} \leq 0,05)$ no grupo

\section{Quadro 1. Média e desvio padrão do Consumo de ração Médio (CRM), Ganho de peso total (GPT), Ganho de peso médio (GPM) e Conversão alimentar (CA) de 1-21 dias de idade nos diferentes tratamentos}

\begin{tabular}{lccccc}
\hline \multicolumn{1}{c}{ Tratamento } & $\begin{array}{c}\text { Repetições } \\
\text { (n) }\end{array}$ & CRM (g) & GPT (g) & GPM (g) & CA \\
\hline AO* na ração & 4 & $1123,8 \pm 26,8$ & $11136,7 \pm 1072,6$ & $751,3 \pm 58,5$ & $1,504 \pm 0,138$ \\
AO na ração e na água & 4 & $1111,8 \pm 18,8$ & $10883,7 \pm 216,5$ & $728,0 \pm 14,1$ & $1,528 \pm 0,03$ \\
Controle & 4 & $1101,2 \pm 37,1$ & $10198,2 \pm 710,4$ & $691,5 \pm 53,0$ & $1,597 \pm 0,091$ \\
Valor de P & & 0,629 & 0,1549 & 0,1515 & 0,1558 \\
\hline
\end{tabular}

*AO = ácido orgânico.

Quadro 2. Média e desvio padrão da Contagem de Salmonella Enteritidis (SE), Log10 UFC, em swab de cloaca (48h pós-inoculação com SE). Número de amostras positivas em relação ao total de amostras para $S E$ em ceco e papo de frangos de corte 7 dias pós-inoculação com SE, nos diferentes tratamentos

\begin{tabular}{lcccc}
\hline \multicolumn{1}{c}{ Tratamento } & $\begin{array}{c}\text { Repetições } \\
(\mathrm{n})\end{array}$ & $\begin{array}{c}\text { Swab de cloaca } \\
48 \mathrm{~h} \text { PI }\end{array}$ & $\begin{array}{c}\text { Ceco - Amostras } \\
\text { positivas (7dias PI) }\end{array}$ & $\begin{array}{c}\text { Papo - Amostras } \\
\text { positivas (7dias PI) }\end{array}$ \\
\hline A0* na ração & 12 & $2,60 \pm 1,62$ & $2 / 12 \mathrm{a}$ & $4 / 12 \mathrm{a}$ \\
AO na ração e na água & 12 & $2,20 \pm 1,66$ & $1 / 12 \mathrm{a}$ & $4 / 12 \mathrm{a}$ \\
Controle & 12 & $2,85 \pm 1,64$ & $11 / 12 \mathrm{~b}$ & $10 / 12 \mathrm{~b}$ \\
Valor de P & & 0,7690 & 0,050 & 0,05
\end{tabular}

*AO = ácido orgânico, PI = pós inoculação com Salmonella Enteritidis.

ab Letras diferentes na mesma coluna são significativamente diferentes para $\mathrm{P} \leq 0,05$ ao teste de Qui-quadrado. 
Quadro 3. Média e desvio padrão da altura de vilo $(\mu \mathrm{m})$, profundidade de criptas $(\mu \mathrm{m})$, relação vilo/cripta, contagem de células caliciformes, contagem de células CD3+/campo em duodeno, jejuno, íleo e ceco (21 dias de idade e 7 dias pós inoculação com Salmonella Enteritidis) nos diferentes tratamentos. $(n=20)$

\begin{tabular}{|c|c|c|c|c|c|c|}
\hline Fragmento & Variável & $\begin{array}{l}\text { Repetições } \\
\text { (n) }\end{array}$ & A0* na ração & $\begin{array}{c}\text { A0 na ração e } \\
\text { na água }\end{array}$ & Controle & Valor de $\mathrm{P}$ \\
\hline \multirow[t]{5}{*}{ Duo } & Vilo & 20 & $971,4 \pm 221,9^{b}$ & $1138,5 \pm 300,4^{\mathrm{a}^{* *}}$ & $1284,4 \pm 234,2^{\mathrm{a}}$ & 0,0012 \\
\hline & Cripta & 20 & $97,1 \pm 27,1$ & $99,5 \pm 30,0$ & $83,3 \pm 17,0$ & 0,0998 \\
\hline & Vilo/Cripta & 20 & $10,7 \pm 3,5^{b}$ & $12,3 \pm 4,6^{b}$ & $16,0 \pm 4,2^{\mathrm{a}}$ & 0,0006 \\
\hline & Caliciforme/Vilo & 20 & $160,9 \pm 35,8$ & $165,3 \pm 36,6$ & $178,6 \pm 54,5$ & 0,4071 \\
\hline & CD3+/Campo & 10 & $16,9 \pm 3,7$ & $18,9 \pm 3,5$ & $17,8 \pm 5,1$ & 0,695 \\
\hline \multirow[t]{5}{*}{ Jej } & Vilo & 20 & $1256 \pm 268,3$ & $1225,4 \pm 225,8$ & $1288,0 \pm 188,8$ & 0,0968 \\
\hline & Cripta & 20 & $105,1 \pm 26,1^{\mathrm{b}}$ & $107,2 \pm 20,8^{\mathrm{b}}$ & $145,3 \pm 17,9$ a & 0,0001 \\
\hline & Vilo/Cripta & 20 & $12,7 \pm 4,2^{\mathrm{a}}$ & $11,6 \pm 2,2^{\mathrm{a}}$ & $9,0 \pm 1,8^{\mathrm{b}}$ & 0,0015 \\
\hline & Caliciforme/Vilo & 20 & $132,6 \pm 36,2^{b}$ & $120,6 \pm 24,1^{b}$ & $152,8 \pm 33,7^{\text {a }}$ & 0,0016 \\
\hline & CD3+/Campo & 10 & $14,0 \pm 4,0^{\mathrm{b}}$ & $15,5 \pm 5,7^{\mathrm{b}}$ & $23,6 \pm 6,9^{a}$ & 0,002 \\
\hline \multirow[t]{5}{*}{ Íleo } & Vilo & 20 & $498,5 \pm 65,6^{b}$ & $514,4 \pm 88,7^{b}$ & $663,8 \pm 98,3^{\text {a }}$ & 0,0001 \\
\hline & Cripta & 20 & $79,1 \pm 17,0 \mathrm{a}$ & $97,7 \pm 16,4 \mathrm{~b}$ & $121,5 \pm 31,4 \mathrm{c}$ & 0,0001 \\
\hline & Vilo/Cripta & 20 & $6,5 \pm 1,5$ & $5,3 \pm 1,0$ & $5,9 \pm 2,0$ & 0,2378 \\
\hline & Caliciforme/Vilo & 20 & $129,7 \pm 21,7^{\mathrm{a}}$ & $101,1 \pm 32,0^{b}$ & $138,6 \pm 21,2^{a}$ & 0,0001 \\
\hline & CD3+/Campo & 10 & $18,9 \pm 6,1$ & $17,0 \pm 2,2$ & $23,50 \pm 4,5$ & 0,020 \\
\hline \multirow[t]{5}{*}{ Ceco } & Vilo & 20 & $276,5 \pm 81,6^{\mathrm{a}}$ & $212,6 \pm 47,0^{b}$ & $243,4 \pm 59,3^{a b}$ & 0,0106 \\
\hline & Cripta & 20 & $131,6 \pm 41,7^{\mathrm{a}}$ & $99,8 \pm 24,5^{b}$ & $124,8 \pm 41,2^{a}$ & 0,0206 \\
\hline & Vilo/Cripta & 20 & $2,3 \pm 1,0$ & $2,3 \pm 0,9$ & $2,2 \pm 1,1$ & 0,9520 \\
\hline & Caliciforme/Vilo & 20 & $8,9 \pm 5,7$ & $9,2 \pm 5,1$ & $12,0 \pm 9,3$ & 0,0001 \\
\hline & CD3+/Campo & 10 & $19,2 \pm 7,5$ & $14,0 \pm 4,0$ & $17,4 \pm 4,0$ & 0,3137 \\
\hline
\end{tabular}

tratado somente com ácidos orgânicos na ração quando comparado aos demais grupos. Em jejuno, não foram observadas diferenças significativas entre os tratamentos. No íleo dos animais tratados com ácidos orgânicos na ração e na ração e na água observa-se altura de vilosidade significativamente menor $(\mathrm{P} \leq 0,05)$ quando comparado ao grupo controle. Em ceco, observa-se menor altura de vilo no grupo tratado com ácidos orgânicos na ração e na água quando comparado ao grupo onde utilizou-se somente ácidos orgânicos na ração $(\mathrm{P} \leq 0,05)$.

Em duodeno não foram observadas diferenças significativas na variável profundidade de cripta. Porém, em jejuno e íleo obteve-se maior profundidade no grupo controle quando comparado aos demais grupos $(\mathrm{P} \leq 0,05)$. No ceco observou-se menor profundidade no grupo tratado com ácidos na ração e na água quando comparado aos demais grupos $(\mathrm{P} \leq 0,05)$.

Na relação altura de vilosidade/profundidade de cripta obteve-se relação significativamente maior $(\mathrm{P} \leq 0,05) \mathrm{em}$ duodeno no grupo controle. Em jejuno observa-se menor relação no grupo controle se comparado aos demais grupos. Em íleo e ceco não foram observadas diferenças significativas entre os tratamentos.

Com relação à variável número de células caliciformes, em duodeno não foram observadas diferenças significativas entre os tratamentos. Em jejuno, o grupo controle inoculado obteve maior número de células caliciformes quando comparado aos demais grupos analisados. Em íleo, o grupo tratado com ácidos orgânicos na ração e na água obteve contagem significativamente menor de células caliciformes, quando comparado aos demais grupos $(\mathrm{P} \leq 0,05)$. Em ceco, o grupo controle inoculado obteve quantidade estatisticamente maior de células caliciformes que os demais grupos $(\mathrm{P} \leq 0,05)$.
Com relação à presença de células $\mathrm{CD} 3+$ na mucosa intestinal observaram-se somente diferenças estatísticas em jejuno e íleo onde o grupo controle inoculado com SE apresentou maior número de células quando comparado aos demais grupos $(\mathrm{P} \leq 0,05)$.

Citometria de fluxo. No Quadro 4 estão apresentados os dados de citometria de fluxo aos 21 dias de idade dos animais e 7 dias pós-inoculação com SE, nos diferentes tratamentos. Observa-se proporção significativamente maior $(\mathrm{P} \leq 0,05)$ de células $\mathrm{CD} 4, \mathrm{CD} 28$ e nos receptores de linfócitos de mucosa TCR $\alpha \beta$ V $\beta 1$ e TCR $\alpha \beta$ V $\beta 2$ no sangue de animais do grupo tratado somente com ácido na ração, quando comparado aos demais grupos.

\section{Experimento 2}

Análise de Salmonella. O Quadro 5 apresenta os resultados da média e desvio padrão da Contagem de Salmonella Minnesota (SM), resultados transformados em Log10 Unidades Formadoras de Colônias (UFC/g) em swab de cloaca 48 horas após inoculação (22 dias de idade), em papo e em ceco aos 7 dias após inoculação com SM (28 dias de idade). É possível observar que 48 horas após inoculação com Salmonella Minnesota todos os animais inoculados apresentavam excreção de Salmonella. Observa-se que em papo com 7 dias pós inoculação os tratamentos com ácidos orgânicos na ração e ácidos orgânicos na ração e na água obtiveram menor contagem de Salmonella, quando comparado ao controle positivo. Em ceco não foram encontradas diferenças significativas entre os grupos tratados com ácidos orgânicos e o grupo inoculado sem tratamento. 0 controle negativo (não inoculado com SM) não apresentou contagem de SM em nenhum período.

Morfologia intestinal e imuno-histoquímica. 0 Qaudro 6 apresenta os resultados da média e do desvio 
Quadro 4. Média e Desvio padrão das proporções de células circulantes no sangue de frangos de corte aos 21 dias de idade e após 7 dias da inoculação com SE, de acordo com a subpopulação identificada (ou a razão entre as populações CD4+ e CD8+). $(n=4)$

\begin{tabular}{lccccc}
\hline $\begin{array}{c}\text { Molécula de } \\
\text { superfície }\end{array}$ & $\begin{array}{c}\text { Repetições } \\
(\mathrm{n})\end{array}$ & AO* na ração & $\begin{array}{c}\text { AO na ração e } \\
\text { na água }\end{array}$ & Controle & Valor de P \\
\hline CD4 & 4 & $41,53 \pm 13,83 \% \mathrm{a}^{* *}$ & $15,34 \pm 4,66 \% \mathrm{~b}$ & $15,17 \pm 3,18 \% \mathrm{~b}$ & 0,0001 \\
CD8 $\alpha$ & 4 & $17,50 \pm 4,31 \%$ & $9,50 \pm 10,08 \%$ & $7,11 \pm 1,85 \%$ & 0,0571 \\
CD8 $\alpha^{\text {Hight }}$ & 4 & $1,16 \pm 0,43 \%$ & $0,60 \pm 0,53 \%$ & $0,33 \pm 0,17 \%$ & 0,3666 \\
CD28 & 4 & $54,72 \pm 22,5 \mathrm{a}$ & $24,17 \pm 9,41 \% \mathrm{~b}$ & $17,48 \pm 7,80 \% \mathrm{~b}$ & 0,0001 \\
CD4:CD8 $\alpha$ & 4 & $2,33 \pm 0,27$ & $2,88 \pm 1,81$ & $2,24 \pm 0,69$ & 0,3467 \\
CD8 $\beta$ & 4 & $6,75 \pm 3,70 \%$ & $4,33 \pm 2,30 \%$ & $2,66 \pm 0,62 \%$ & 0,3567 \\
MHC I & 4 & $3,60 \pm 1,40 \%$ & $1,50 \pm 0,38 \%$ & $1,14 \pm 0,50 \%$ & 0,4432 \\
MHC II & 4 & $20,87 \pm 12,90 \%$ & $10,86 \pm 2,02 \%$ & $11,78 \pm 4,31 \%$ & 0,0762 \\
MHC II ${ }^{\text {Bright }}$ & 4 & $1,75 \pm 0,80 \%$ & $1,97 \pm 0,87 \%$ & $0,99 \pm 0,36 \%$ & 0,6045 \\
TCR $\alpha \beta$ V $\beta 1$ & 4 & $40,21 \pm 19,75 \%$ a & $13,10 \pm 5,5 \%$ b & $8,25 \pm 2,98 \%$ b & 0,0001 \\
TCR $\alpha \beta$ V $\beta 2$ & 4 & $19,16 \pm 4,26 \%$ a & $7,22 \pm 5,43 \%$ b & $4,60 \pm 1,09 \%$ b & 0,0009 \\
${ }^{*}$ A0 = ácido orgânico. ${ }^{* *}$ Letras diferentes na mesma linha diferem estatisticamente pelo teste do \\
Qui-Quadrado $(\mathrm{P}<0,05)$.
\end{tabular}

padrão da altura de vilosidade $(\mu \mathrm{m})$, profundidade de criptas $(\mu \mathrm{m})$, relação vilo/cripta, contagem de células caliciformes, contagem de células CD3+/campo em duodeno, jejuno, íleo e ceco de frangos nos diferentes tratamentos aos 28 dias de idade e 7 dias pós inoculação com Salmonella Minnesota.

Observa-se que na altura de vilosidade, não foram encontradas diferenças significativas $(\mathrm{P} \leq 0,05)$ em duodeno. Porém, em jejuno, obteve-se menor altura de vilosidade no tratamento onde foi utilizado ácido orgânico na ração e na água quando comparado aos demais tratamentos. Em íleo obteve-se menor altura de vilosidade $(\mathrm{P} \leq 0,05)$ no grupo tratado somente com ácido orgânico na ração quando comparado aos demais tratamentos. Em ceco, o grupo não inoculado e grupo inoculado com SM e tratado com ácidos orgânicos na ração e na água obtiveram maior altura de vilosidade quando comparado aos demais grupos.

Com relação à variável profundidade de cripta não foram observados diferenças estatísticas entre os tratamentos em nenhum segmento intestinal.

Na variável vilo/cripta foi observada diferença estatística somente no ceco onde se obteve maior relação no grupo não inoculado com SM e menor relação no grupo inoculado com SM e não tratado. Os demais grupos apresentaram valores de relação vilo/cripta intermediários, porém semelhantes estatisticamente.

A variável contagem de células caliciformes somente em duodeno e jejuno foi possível observar diferenças significativas entre os tratamentos. Em duodeno o grupo não

Quadro 5. Média e desvio padrão da Contagem de Salmonella Minnesota (SM), Log10 UFC/g, em swab de cloaca (48h pós-inoculação com SM), papo e ceco de frangos de corte (7 dias pós-inoculação com SM)

\begin{tabular}{ccccc}
\hline Tratamentos & $\begin{array}{c}\text { Repetições } \\
(\mathrm{n})\end{array}$ & $\begin{array}{c}\text { Swab de cloaca } \\
(48 \mathrm{~h} \mathrm{PI})\end{array}$ & $\begin{array}{c}\text { Papo } \\
(7 \text { dias PI) }\end{array}$ & $\begin{array}{c}\text { Ceco } \\
(7 \text { dias PI) }\end{array}$ \\
\hline Controle Negativo & 18 & $0,0 \pm 0,00 \mathrm{~b}^{* *}$ & $0,0 \pm 0,00 \mathrm{c}$ & $0,0 \pm 0,00 \mathrm{~b}$ \\
Controle Positivo & 18 & $5,0 \pm 0,40 \mathrm{a}$ & $3,8 \pm 1,40 \mathrm{a}$ & $4,7 \pm 1,00 \mathrm{a}$ \\
A0* na ração & 18 & $5,0 \pm 0,32 \mathrm{a}$ & $2,5 \pm 1,50 \mathrm{~b}$ & $4,6 \pm 1,50 \mathrm{a}$ \\
AO na ração e na água & 18 & $4,8 \pm 0,30 \mathrm{a}$ & $2,0 \pm 1,60 \mathrm{~b}$ & $3,8 \pm 1,60 \mathrm{a}$ \\
Valor de P & & 0,0001 & 0,0001 & 0,0001 \\
\hline
\end{tabular}

*AO = ácido orgânico. ** Letras diferentes na mesma coluna diferem estatisticamente $(\mathrm{P}<0,05)$. inoculado apresentou maior contagem de células caliciformes que os demais tratamentos. Em jejuno, o controle não inoculado com SM apresentou maior contagem de células caliciformes, em seguida, o controle inoculado com SM e não tratado e do grupo tratado com ácido na ração. 0 grupo inoculado e tratado com ácidos orgânicos na ração e na água apresentou contagem significativamente menor de células caliciformes em relação aos demais grupos.

Com relação aos dados de contagem de células CD3+ em duodeno, observou-se que os grupos inoculados e tratados com ácidos orgânicos na ração e na ração e na água apresentaram contagem significativamente menor que os demais grupos $(\mathrm{P} \leq 0,05)$. Em jejuno, o controle não inoculado com SM (controle negativo) apresentou menor contagem de células CD3+ em relação aos demais tratamentos, e o grupo inoculado e tratado com ácidos orgânicos na ração e na água apresentou contagem significativamente maior de células CD3+ que os demais tratamentos. Em íleo observa-se que o controle positivo apresentou contagem significativamente maior de células CD3+ quando comparado aos demais grupos. No ceco, o grupo inoculado e tratado com ácidos orgânicos na ração apresentou contagem significativamente maior de células CD3+ em relação aos demais grupos.

A Figura 1 ilustra a comparação entre a porcentagem de redução de SE e SM em papo e ceco de frangos, 7 dias após a inoculação com Salmonella, nos diferentes tratamentos em relação ao grupo controle inoculado de cada experimento. Pode-se observar redução de $60 \%$ da excreção de SE no papo de aves tratadas via ração ou via ração e água em relação ao grupo inoculado e não tratado, não havendo diferença entre as vias de tratamento $(\mathrm{P} \leq 0,05)$. Quando se compara a eficácia de redução de excreção de Salmonella no grupo inoculado com SM observa-se que os produtos adicionados na ração ou na ração e na água reduziram no papo a contagem de SM em 34,3\% e 47,4\% respectivamente, quando comparado ao grupo inoculado e não tratado. Essa porcentagem de redução de Salmonella no papo com a utilização de ácidos orgânicos na ração ou ração e água é significativamente diferente entre grupos inoculados com SE e SM $(P \leq 0,05)$. No ceco houve redução de $81,2 \%$ no iso- 
Quadro 6. Média e desvio padrão da altura de vilo $(\mu \mathrm{m})$, profundidade de criptas $(\mu \mathrm{m})$, relação vilo/cripta, contagem de células caliciformes, contagem de células CD3+/campo em duodeno, jejuno, íleo e ceco (28 dias de idade e 7 dias pós inoculação com Salmonella Minnesota) nos diferentes tratamentos.(n=20)

\begin{tabular}{cccccccc}
\hline Fragmento & Variável & $\begin{array}{c}\text { Repetições } \\
\text { (n) }\end{array}$ & Controle negativo & Controle positivo & AO* na ração & AO na ração e na água & Valor de P \\
& & & & & & \\
\hline Duo & Vilo & 20 & $1644,1 \pm 505,7$ & $1489,8 \pm 265,7$ & $1328,2 \pm 533,0$ & $1765,4 \pm 186,6$ & 0,1719 \\
& Cripta & 20 & $201,6 \pm 100,0$ & $134,7 \pm 46,7$ & $133,1 \pm 48,8$ & $152,1 \pm 56,5$ & 0,587 \\
& Vilo/Cripta & 20 & $9,35 \pm 4,4$ & $12,0 \pm 4,1$ & $10,2 \pm 3,2$ & $12,9 \pm 4,5$ & 0,1791 \\
& Caliciforme/Vilo & 20 & $196,1 \pm 87,6 \mathrm{a}$ & $110,3 \pm 56,6 \mathrm{~b}$ & $61,3 \pm 26,4 \mathrm{~b}$ & $116,1 \pm 31,3 \mathrm{~b}$ & 0,0002 \\
& CD3+/Campo & 10 & $11,5 \pm 4,2 \mathrm{a}$ & $13,8 \pm 2,6 \mathrm{a}$ & $10,0 \pm 3,7 \mathrm{~b}$ & $9,7 \pm 3,5 \mathrm{~b}$ & 0,0505 \\
Jej & Vilo & 20 & $871,9 \pm 209,4 \mathrm{a}$ & $773,5 \pm 163,5 \mathrm{ab}$ & $899,7 \pm 230,2 \mathrm{a}$ & $692,5 \pm 137,6 \mathrm{~b}$ & 0,0150 \\
& Cripta & 20 & $97,3 \pm 36,3$ & $99,7 \pm 35,0$ & $110,18 \pm 43,0$ & $87,1 \pm 37,3$ & 0,4307 \\
& Vilo/Cripta & 20 & $9,8 \pm 3,6$ & $8,4 \pm 2,6$ & $8,8 \pm 3,2$ & $9,0 \pm 3,3$ & 0,6619 \\
& Caliciforme/Vilo & 20 & $129,2 \pm 30,8 \mathrm{a}$ & $78,7 \pm 38,4 \mathrm{~b}$ & $79,5 \pm 32,3 \mathrm{~b}$ & $54,8 \pm 15,6 \mathrm{c}$ & 0,0001 \\
& CD3+/Campo & 10 & $2,9 \pm 2,3 \mathrm{c}$ & $11,2 \pm 4,8 \mathrm{~b}$ & $11,6 \pm 3,2 \mathrm{~b}$ & $21,3 \pm 5,5 \mathrm{a}$ & 0,0001 \\
Íleo & Vilo & 20 & $798,15 \pm 168,5 \mathrm{a}$ & $622,8 \pm 157,0 \mathrm{~b}$ & $476,4 \pm 119,4 \mathrm{c}$ & $598,5 \pm 134,0 \mathrm{~b}$ & 0,0001 \\
& Cripta & 20 & $97,9 \pm 42,6$ & $80,3 \pm 40,0$ & $75,0 \pm 39,1$ & $82,7 \pm 34,2$ & 0,4231 \\
& Vilo/Cripta & 20 & $10,7 \pm 8,4$ & $10,8 \pm 10,3$ & $7,4 \pm 2,6$ & $8,0 \pm 2,7$ & 0,3863 \\
& Caliciforme/Vilo & 20 & $92,3 \pm 33,0$ & $77,4 \pm 38,0$ & $67,0 \pm 24,4$ & $64,6 \pm 28,9$ & 0,0757 \\
& CD3+Campo & 10 & $14,2 \pm 7,0 \mathrm{~b}$ & $25,0 \pm 8,5 \mathrm{a}$ & $11,4 \pm 5,4 \mathrm{~b}$ & $13,1 \pm 3,6 \mathrm{~b}$ & 0,0001 \\
Ceco & Vilo & 20 & $322,3 \pm 91,4 \mathrm{a}$ & $235,1 \pm 38,0 \mathrm{~b}$ & $274,7 \pm 27,1 \mathrm{ab}$ & $303,9 \pm 60,1 \mathrm{a}$ & 0,0026 \\
& Cripta & 20 & $129,7 \pm 60,9$ & $117,6 \pm 33,1$ & $151,0 \pm 23,4$ & $131,0 \pm 43,8$ & 0,3716 \\
& Vilo/Cripta & 20 & $3,0 \pm 1,5 \mathrm{a}$ & $2,1 \pm 0,5 \mathrm{~b}$ & $1,8 \pm 0,3 \mathrm{ab}$ & $2,5 \pm 1,0 \mathrm{ab}$ & 0,0366 \\
& Caliciforme/Vilo & 20 & $6,1 \pm 2,7$ & $9,0 \pm 5,1$ & $4,5 \pm 2,7$ & $6,0 \pm 4,7$ & 0,0614 \\
& CD3+/Campo & 10 & $6,1 \pm 2,7 \mathrm{~b}$ & $4,8 \pm 2,4 \mathrm{~b}$ & $13,4 \pm 3,3 \mathrm{a}$ & $5,8 \pm 3,0 \mathrm{~b}$ & 0,0001 \\
\hline
\end{tabular}

${ }^{*} \mathrm{AO}=$ ácido orgânico. Duo = duodeno. Jej $=$ jejuno. ${ }^{* *}$ Letras diferentes na mesma linha diferem estatisticamente $(\mathrm{P}<0,05)$.

$\%$

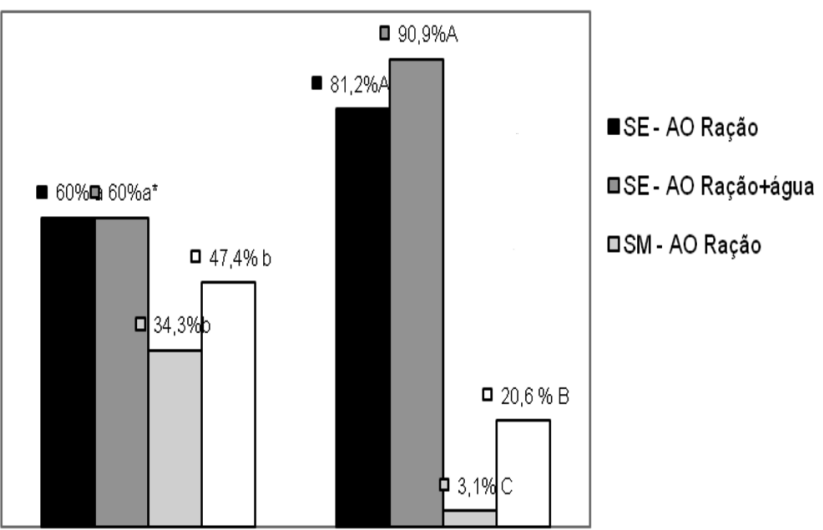

Fig.1. Porcentagem (\%) de redução de Salmonella Enteritidis (SE) e Salmonella Minnesota (SM) em relação ao grupo controle inoculado em papo e ceco de frangos 7 dias após inoculação nos diferentes tratamentos (AO = ácido orgânico). *ab Letras diferente entre colunas diferem significativamente ao teste de Qui-Quadrado a 5\% de Probabilidade em papo. ${ }^{\mathrm{ABC}}$ Letras diferentes entre colunas diferem significativamente ao teste de Qui-Quadrado a 5\% de probabilidade em ceco.

lamento de Salmonella no grupo inoculado com SE para o grupo tratado com ácidos orgânicos na ração e 90,9\% para o grupo tratado com ácidos orgânicos na ração e na água, quando comparado ao grupo inoculado, não havendo diferença de porcentagem de redução da presença de Salmonella entre os grupos tratados com ácidos. Para os animais inoculados com SM a redução de isolamento de Salmonella no tratamento com ácidos orgânicos somente na ração foi de $3,1 \%$, significativamente menor que o grupo tratado com ácidos orgânicos na ração e na água cuja redução com relação ao grupo inoculado foi de 20,6\%. Quando se compara a eficácia de redução da presença de Salmonella no ceco entre grupos inoculados com SM e SE, verifica-se significativa diferença $(P \leq 0,05)$ entre a eficácia de redução, onde o tratamento com ácidos orgânicos foram eficientes em animais inoculados com SE, mas não para SM, embora as condições em que os experimentos foram desenvolvidos tenham sido diferentes.

Com relação à inoculação dos animais, no primeiro experimento, aos 7 dias pós-inoculação, houve isolamento de Salmonella em papo e ceco mas não foi possível obter quantidade suficiente que permitisse a contagem deste microorganismo para nenhum dos tratamentos estudados. Isso pode ter ocorrido devido a dose desafio que foi inoculada nas aves, a interação entre o parasita, hospedeiro e ambiente, causando a diminuição da excreção de SE. Nas aves inoculadas com SE e não tratadas com ácidos orgânicos, foi possível se observar no exame clínico diarréia e na necropsia enterite mucóide. No segundo experimento, optou-se por inocular as aves com uma concentração de $10^{8} \mathrm{UFC} / \mathrm{mL}$ de SM devido a estudos prévios indicarem que com concentrações abaixo deste valor não possibilitaram excreção desta bactéria. No que se refere ao exame clínico e necropsia, aves inoculadas com SM não apresentaram sinais e lesões, podendo-se especular que a SM é menos patogênica do que SE para as aves.

Quando comparamos a porcentagem de redução de SE e SM proporcionada pelo tratamento com ácidos orgânicos em relação aos respectivos grupos inoculados e não tratados, observamos que tanto em papo quanto em ceco, o tratamento com ácidos orgânicos reduziu a porcentagem de animais positivos para SE, mais do que verificado quando se inoculou SM. A maioria da literatura tem comprovado que ácidos orgânicos são efetivos no controle de SE (Sterzo et al. 2007, Bassan et al. 2008) entretanto, não existem estudos apresentando a eficácia destes contra SM. O mecanismo de ação dos ácidos orgânicos sobre Salmonella pode ser direto sobre esta bactéria através da teoria dos ácidos fracos (Cherrington et al. 1991, Roth \& Kirchgessner 1998) ou 
por alteração da membrana celular (Stratford et al. 2009). Entretanto também sugere-se que os ácidos orgânicos podem reduzir a contagem de coliformes e aumentar bactérias lácticas na microbiota intestinal e pelo mecanismo de exclusão competitiva diminuir a viabilidade da Salmonella (Pirgozliev et al. 2008).

A eficácia dos ácidos orgânicos, de acordo com a via de administração do produto utilizado, também variou conforme o sorotipo inoculado. Para aves inoculadas com SE a adição dos ácidos orgânicos na ração ou na ração e na água não mostrou diferença de eficácia na presença de Salmonella em papo e ceco. Já para SM a adição do produto na água, além do já existente via ração, aumentou a eficiência de ácidos orgânicos em reduzir a Salmonella no ceco, porém o mesmo não foi observado em papo, sugerindo uma diferente interação da SM com o hospedeiro e a microbiota intestinal do que aquela observada com SE.

Um importante resultado deste trabalho refere-se à resposta do sistema imunológico das aves à inoculação de Salmonella. No primeiro experimento, utilizando citometria de fluxo, foi possível observar maior proporção de células CD4, CD28 e nos receptores de linfócitos de mucosa TCR $\alpha \beta$ V $\beta 1$ e TCR $\alpha \beta$ V $\beta 2$ no sangue das aves do grupo tratado com ácidos orgânicos na ração, quando comparado aos demais grupos. Esses resultados contrastam com o menor número de células CD3+ e células caliciformes na mucosa intestinal do jejuno e íleo nas aves dos grupos tratados com ácidos orgânicos na ração e na ração e na água quando comparado ao controle. Também, foi demonstrada redução no número de células $\mathrm{CD}^{+}{ }^{+}$e $\mathrm{CD}^{+}{ }^{+}$no sangue periférico de galinhas infectadas com Sallmonella Enteritidis em comparação com o grupo controle não-infectado. Neste caso, sugere-se que esse fenômeno está relacionado à migração destas células para o sitio de ação da infecção, com redução de sua expressão no sangue (Asheg et al. 2003). Em aves vacinadas e submetidas à infecção com Salmonella Enteritidis, foi observado aumento da quantidade de células citotóxicas no ceco indicando saída de células da circulação com destino ao tecido desafiado (Berndt et al. 2006). Aves têm três diferentes receptores de linfócito T (TCR), TCR $\gamma \delta$ (TCR1), TCR $\alpha \beta$ V $\beta 1$ (TCR2) e TCR $\alpha \beta$ V $\beta 2$. Neste trabalho, os dois últimos marcadores foram utilizados e observaram-se diferenças significativas entre os grupos, compatível com menor proporção deste no sangue de aves desafiadas com SE e não tratadas com ácidos orgânicos. Cada célula individual expressa apenas um tipo de TCR em sua superfície, e os três tipos podem estar presentes tanto em células CD4 quanto CD8 (Sowder et al. 1988, Davidson et al. 1992, Berndt et al. 2006). Acredita-se que o TCR2 esteja envolvido na imunidade de mucosa, ao estimular a produção de IgA (Cihak et al. 1991, Zuckerman 1999). CD28+ é um receptor de coestimulação da ativação de células T, quando entra em contato com células apresentadoras de antígeno. A interação entre CD28 e B7 é essencial para a montagem da resposta imune (Linsley \& Ledbetter 1993). A redução na proporção de CD28+ circulante, como foi observada no grupo controle desafiado e não tratado no presente estudo, é visto na fase aguda de processos infecciosos devido ao destinamento dessas células para os órgãos linfóides secundários, em um processo conhecido como homing ou devido à excessiva ativação e consequente senescência das células, em um processo em que a molécula CD28 é perdida (Nabeshima et al. 2002, Papagno et al. 2004).

O Complexo de Histocompatibilidade Maior de classe I (MHC - I), conhecido em aves como o antígeno F, está presente em todos os linfócitos e eritrócitos de galinhas (Yamaiuchi \& Isshiki 1991). O MHC II, ou antígeno L, está presente na maioria dos linfócitos bursa-dependentes. Cerca de $10 \%$ dos linfócitos são positivos para MHC II, e desses, aparentemente cerca de $90 \%$ são linfócitos B (Hála et al. 1981). A marcação para MHC II também demonstra uma subpopulação que tem alta expressão dessas moléculas.

Com relação à morfologia intestinal, quanto maior o número de células, maior o tamanho das vilosidades e, consequentemente, maior a área de absorção dos nutrientes (Yamauchi \& Isshiki 1991). Para a relação vilosidade/ cripta intestinal é desejável que as vilosidades apresentem-se altas e as criptas rasas (Nabuurs 1995). A profundidade da cripta pode indicar o nível de hiperplasia das células intestinais; sendo que a redução da profundidade indica menor nível de agressão à morfologia da parede intestinal (Hancok et al. 1990). Ácidos orgânicos, aminoácidos e prebióticos estimulam o desenvolvimento da mucosa intestinal causando aumento do número de células e consequentemente aumento do tamanho das vilosidades (Maiorka et al. 2004). Esta relação pode ser confirmada em experimentos sem desafio, porém, verifica-se hoje em experimentos com animais desafiados, que tão importante quanto a altura da vilosidade é o conhecimento do tipo celular presente nessa vilosidade, como observado neste experimento. As células caliciformes são as células produtoras de glicoproteínas (muco) que tem as funções de proteção da mucosa intestinal contra agentes abrasivos da dieta e agentes patogênicos e também, participa na absorção dos nutrientes. 0 muco participa da resposta imune inespecífica, e quando há a grande expressão de células caliciformes indica que pode haver algum tipo de desafio sanitário que demande maior produção de muco. Em contrapartida, o muco quando em grandes quantidades pode trazer prejuízos para a saúde da ave, pois aumenta o trânsito intestinal, reduzindo a absorção dos nutrientes. Já as células $\mathrm{CD} 3+$ são linfócitos $\mathrm{T}$, que participam da resposta imune específica do animal.

No presente estudo, com relação aos tipos celulares, na mucosa do jejuno, o grupo controle inoculado com SE apresentou maiores quantidades de células caliciformes e de células CD3+ comparado aos grupos tratados com ácidos orgânicos, isso pode indicar que, por estes ácidos orgânicos controlarem a infecção por SE, visto pela redução do isolamento, diminuiu-se a necessidade de expressão de células caliciformes e menor ativação de células CD3+ na mucosa.

No caso especifico da inoculação com SE, verifica-se uma resposta clássica de desafio e resposta do hospedeiro, ou seja, o grupo inoculado apresentou maior excreção de Salmonella, maior numero de células CD3+ na mucosa intestinal e diminuição na proporção de marcadores de 
células imunológicas no sangue dos animais. 0 controle de Salmonella demonstrado pelos ácidos na análise microbiológica culminou com resposta imunológica menos intensa da ave (menor presença de células CD3+ e maior proporção de marcadores de células imunológicas no sangue dos animais). Já no segundo experimento, na análise microbiológica não se verifica, no ceco, diminuição da excreção de Salmonella em aves inoculadas e tratadas com ácidos orgânicos. Os resultados da morfometria também são bastante contraditórios entre os grupos inoculados com SM e tratados com ácidos orgânicos. Entretanto quando se compara o controle inoculado com o controle negativo não inoculado, observa-se que o primeiro grupo (inoculado) apresenta menor proporção de células caliciformes e maior proporção de células CD3+ na mucosa do duodeno, jejuno e íleo quando comparado ao grupo não inoculado. Isso demonstra uma resposta do hospedeiro frente à inoculação em todos esses segmentos, mas não deixa claro qual a interação da SM com a microbiota intestinal e com a saúde destas aves, já que não são observados sinais clínicos e tampouco lesões intestinais. Acredita-se que maiores estudos são necessários para se compreender melhor esta interação entre SM e hospedeiro.

\section{CONCLUSÕES}

Nas condições em que foram conduzidos os dois experimentos observa-se que na avaliação microbiológica, os ácidos orgânicos reduzem significativamente a excreção de SE em papo e ceco de frangos, independente da via de administração, porém são pouco efetivos no controle de SM.

Com relação à avaliação imunológica, observa-se que a diminuição no isolamento de Salmonella, no grupo inoculado com SE e tratado com ácidos orgânicos na ração está correlacionado com maiores proporções de células com marcadores CD4 e CD8, TCR no sangue e menores proporções de células CD3+ na mucosa intestinal das aves.

Para SM foi observada uma reação imunológica a inoculação, demonstrado pelo maior número de células caliciformes e menor número de células CD3+ na mucosa intestinal dos animais não inoculados e uma relação inversa nos animais inoculados com SM, porém mais estudos são necessários para a compreensão da interação entre SM e hospedeiro.

Agradecimentos.- À Sanex Ind. e Com.

\section{REFERÊNCIAS}

Asheg A.A., Levkut M., Revajová V., Sevcikova Z., Kolodzieyski L. \& Pistl J. 2003. Dynamics of lymphocyte subpopulations in immune organs of chicken infected with Salmonella Enteritidis. Acta Vet. Brno 72:359364.

Bassan J.D., Flôres M.L., Antoniazzi T., Bianchi E., Kuttel J. \& Trindade M.M. 2008. Controle da infecção por Salmonella Enteritidis em frangos de corte com ácidos orgânicos e mananoligossacarídeo. Ciência Rural 38:1961-1965.

Berndt A., Pieper J. \& Methner U. 2006. Circulating $\delta \gamma$ T cells in response to Salmonella enterica serovar Enteritidis exposure in chickens. Infect. Immun. 74:3967-3978.
Bopp C.A., Brenner F.W., Wells J.G. \& Strockbine N.A. 2003. Escherichia coli, Shigella and Salmonella, p.459-474. In: Murray P.R., Baron E.J., Pfalter M.A., Tenover F.C. \& Yolken R.H. (Eds), Manual of Clinical Microbiology. ASM, Washington.

Brasil 2003. MAPA, Instrução Normativa no 6 publicada em 26 de agosto de 2003.

Butaye P., Devriese L.A. \& Haesebrouck F. 2003. Antimicrobial growth promoters used in animal feed: effects of less well know antibiotics on Gram-positive bacteria. Clin. Microbiol. Rev. 16:175-188.

Centers of Disease Control 2008. Salmonella Surveillance: Annual Summary, 2006. US Department of Healthn m and Human Services, Atlanta, Georgia. CDC, 101p.

Cherrington C.A., Hinton M. \& Chopra I. 1991. Organic acids chemistry: Antibacterial activity and practical application. Adv. Microbiol. Physiol. 32:87-108.

Cihak J., Lösch U., Hoffmann-Fezer G., Chen C.H., Cooper M.D. \& ZieglerHeitbrock H.W.L. 1991. In vivo depletion of chicken T-cell subsets. Scand. J. Immun. 38:123-129.

Davidson N.J., Chen C.H. \& Boyd R.L.1992. Kinetics of chicken embryonic thymocyte development in ovo and in organ culture. Eur. J. Immunol. 22:1429-1435.

Desmidt M., Ducatelle R. \& Haesebrouck F. 1998. Serological and bacteriological observations on experimental infection with Salmonella Hadar in chickens. Vet. Microbiol. 60:259-269.

Fair J.M., Taylor-McCabe K.J., Shou Y. \& Marrone B.L. 2008. Immunophenotyping of chicken peripheral blood lymphocyte subpopulations: individual variability and repeatability. Vet. Immunol. Immunopathol. 125:268-273.

Hála K., Boyd R. \& Wick G. 1981. Chicken major histocompatibility complex and disease. Scand. J. Immunol. 14:607-616.

Hancock J.D., Peo E.R.J.R. \& Lewis A.J. 1990. Effects of ethanol extraction and heat treatment of soybean flakes on function and morphology of pig intestine. J. Anim. Sci. 68:3244-3251.

Linsley, P.S. and Ledbetter, J.A.1993. The role of the CD28 receptor during $\mathrm{T}$ cell responses to antigen. An. Rev. Immunol. 11:191-212.

Maiorka A., Santin E., Borges S.A., Opalinski M. \& Silva A.V.F. 2004. Emprego de uma mistura de ácidos fumárico, lático, cítrico e ascórbico em dietas iniciais de frangos de corte. Archs Vet. Sci. 9:31-37.

Nabeshima S., Murata M., Kikuchi K., Ikematsu H., Kashiwagi S. \& Hayashi J.A. 2002. Reduction in the number of peripheral CD28+CD8+ T cells in the acute phase of influenza. Clin. Exp. Immunol. 128:339-356.

Nabuurs M.J.A. 1995. Microbiological, structural and functional changes of the small intestine of pigs at weaning. Pig News and Information 16:9397.

National Research Concil - NRC 1994. Nutrient Requirements of Poultry. $9^{\text {th }}$ ed. National Academy Press, Washington, DC.

Papagno L., Spina C.A., Marchant A., Salio M., Rufer N., Little S., Dong T., Chesney G., Waters A., Easterbrook, P., Dunbar, P.R., Sheperd D., Cerundolo V., Emery V., Griffiths P., Conlon C., Mcmichael A.J., Richman D.D., Rowland-Jones S.L. \& Appay V. 2004. Immune activation and CD8+ T-cell differentiation towards senescence in HIV-1 infection. PLOS Biol. 2:173-185.

Pirgozliev V., Murphy T.C., Owens B., George J. \& Mccann M.E.E. 2008. Fumaric and sorbic acid as additives in broiler feed. Res. Vet. Sci. 84:387394.

Rezende C.S.M., Mesquita A.J., Andrade M.A., Stringhini J.H., Chaves L.S., Minafra C.S. \& Lage M.E. 2008. Ácido acético em rações de frangos de corte experimentalmente contaminadas com Salmonella Enteritidis e Salmonella Typhimurium. Revta Bras. Saúde Prod. Anim. 9:516-528.

Roth F.X. \& Kirchgessner M. 1998. Organic acids as feed additives for young pigs: Nutritional and gastrointestinal effects. J. Anim.d Feed Sci. 8:25-33.

Russel J.B.1992. Another explanation for the toxicity of fermentation acids at low pH: Anion accumulation versus uncoupling.J. Appl. Bacteriol. 73:363-370.

Smirnov A., Sklan D., Uni Z. 2004. Mucin dynamics in the chick small intestines are altered by starvation. J. Nutr. 134:736-742. 
Solomons G. \& Fryhle C. 2002. Química Orgânica. Vol.1 e 2. 7a ed.. LTC Livros Técnicos e Científicos, Rio de Janeiro.

Sowder J.T., Chen C.H., Ager L.L., Chan M.M. \& Cooper M.D. 1988. A large subpopulation of avian T cells express a homologue of the mammalian $\mathrm{T} \gamma / \delta$ receptor. J. Exp. Med. 167:315-322.

Sterzo E.V., Paiva J.B., Mesquita A.L., Freitas O.C. \& Berchieri Jr A. 2007. Organic acids and/or compound with defined microorganisms to control Salmonella entérica serovar Enteritidis experimental infection in chickens. Braz. J. Poult. Sci. 9:69-73.
Stratford M., Plumridge A., Nebe-von-Caron G. \& Archer D.B. 2009. Inhibition of spoilage mould conidia by acetic acid and sorbic acid involves different modes of action, requiring modification of the classical weak-acid theory. Int. J. Food Microbiol. 136:37-43.

Yamauchi K.E. \& Isshiki Y. 1991. Scanning electron microscopic observations on the intestinal villi in growing White Leghorns and broiler chicken from 1 to 30 days of age. Brit. Poult. Sci. 32:67-78.

Zuckermann F.A. 1999. Extrathymic CD4/CD8 double positive T cells. Vet. Immunol. Immunopathol. 72: 55-66. 